\title{
Environmental Benefit Analysis of Pumped Storage Power Station
}

\author{
LU Han ${ }^{1, a}$, CHEN Chen ${ }^{1, b}$, HONG Yongyuan ${ }^{1, c}$, LI Wei $^{1, d}$ \\ ${ }^{1}$ Key laboratory of Regional Energy System Optimization(North China Electric Power University), \\ Ministry of Education, Beijing

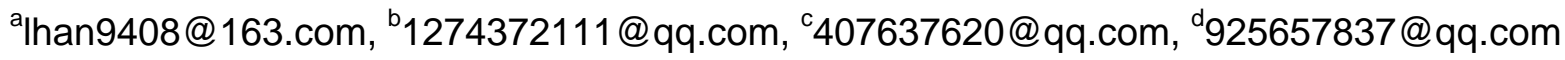

Keywords: pumped storage power station; carbon emissions; environmental benefits

Abstract. Analyzes the carbon emission characteristics of power system before and after the introduction of pumped storage power station. To evaluate the environmental benefits of pumped storage power station combined with new energy peak load. For thermal power, pumped storage thermal power, wind power - pumped storage - thermal power three different scenarios, establish a systematic method for accounting carbon dioxide emissions, measure the carbon emissions at all stages of the power system, obtain the environmental benefits that can be brought by using the pumped storage energy and verify the wind power and other renewable energy sources have the effect of promoting the reduction in power systems.

\section{Introduction}

With the increasingly serious global energy crisis and environmental pollution, energy saving and emission reduction of power system has attracted much attention. To reduce emissions renewable sources must be integrated in the power system. As a special form of power supply, the pumped storage power station can not only peak and fill valley, but also compensate for the intermittent fluctuation of wind, light and other new energy sources ${ }^{[1]}$. It has become an effective and indispensable tool for power system in our country.

\section{Power system operation combined with pumped storage}

About 25\% of China's regional area is rich in wind resources, the coastal areas and the "three North" region as the representative, especially in the northwest. According to the relevant data, the total installed capacity of offshore wind power and wind power in China is about $1.0 \times 10^{9} \mathrm{~kW}^{[2]}$. Therefore, large-scale use of wind power as far as possible is conducive to the development of resource-saving society. However, due to the instability of wind power, large-scale wind power generation has system voltage fluctuations, flicker, harmonics and other issues, and will have an adverse impact on the frequency, supply and demand control of independent power supply and load system. The pumped storage power station has the advantages of fast response, high performance to price ratio, flexible start and stop, good adjustment ability and so on ${ }^{[3]}$. So, it has obvious advantages in the application of large-scale power grid energy storage, as shown in Figure 1. In areas with abundant wind resources, the use of wind power and pumped storage power supply to the grid, not only can stabilize the system voltage, but also can make the wind power output smoothly, plus the wind power network. 


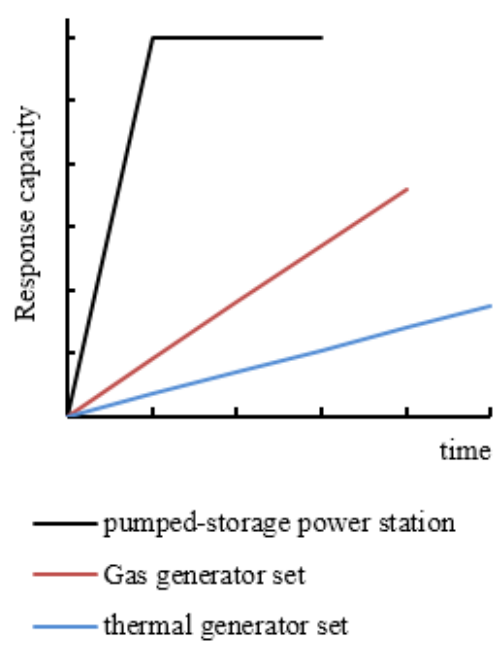

Fig. 1 Load capacity changes under load tracking

The operation characteristics of power generation, transmission, distribution and power consumption are different, there will be some power loss at each stage, and the electricity energy can not be stored. This results in a large workload at the peak of power consumption, and a waste of electricity in the low tide. If possible, the power system has to store energy in periods with "excess supply" and produce in periods with "undersupply", but storage of electrical energy is prohibitively expensive for larger quantities ${ }^{[4]}$. Energy storage technology can be used to improve the low-carbon operation of power system for long periods. As shown in Figure 2, the dotted line represents the average level of electrical load. After the pumped storage power station is involved, the pumped storage power station makes use of excess electricity to pump and store energy at the bottom of the dotted line; At the top of the dotted line, the pumped storage energy is used to generate electricity to fill the shortage of power generation, which can effectively alleviate the problem of safety and excessive pressure caused by high frequency conversion when the generator set is working independently.

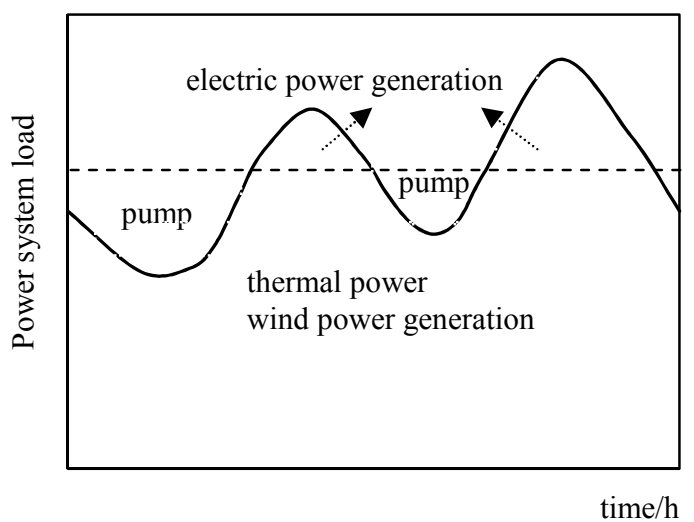

Fig. 2 Daily operation diagram of pumped storage power station

\section{Operating principle of Pumped Storage Power Station}

The pumped storage power station is composed of an upper reservoir, a water reservoir, a water conveyance system and other buildings, it has the double functions of ordinary hydraulic power generation and water pumping station ${ }^{[5]}$. According to the load curve of power system, there is a peak load and a low load in power system. The main energy input of pumped storage power station comes from the valley of load, that is the residual energy of the power grid. The main energy output is used for the peak load.

The following section quantitative analysis of power generation, transmission and distribution process. The greenhouse gas emission accounting method are used to calculate the carbon emissions 
of each link. In order to conclude the energy saving and emission reduction benefits of peak load and valley filling in pumped storage power station. Comparison of carbon emissions in power systems under three different scenarios: thermal power operation alone, pumped storage - thermal power combined operation, wind power - pumped storage power - thermal power combined operation. Besides, quantitative evaluation the environmental benefits of combined pumped storage power system, as well as the indirect carbon emission reduction benefits of peak shaving of renewable energy during peak hours, to provide technical basis for the development of China's power system and energy storage industry.

\section{Environmental benefit analysis of Pumped Storage Power Station}

Scenario 1: joint operation of pumped storage and thermal power

(1) power generation process

Combined with the pumping energy storage power generation process, the maximum environmental benefit is to bear the responsibility of peak shaving, so that the thermal power and other units could stable operation with rated power. In addition, It reduces the coal consumption of frequent start and stop of the traditional thermal power during peaking and valley filling. Therefore, in this case, the carbon dioxide production formula of fuel consumption in the power generation process is:

$$
E_{(1)}=24 \sum_{i=1}^{n} N_{i} b_{i} \alpha_{i}
$$

In the low power consumption, the rated power of the generating unit provides the power consumption of the pumped storage power station. The formula for calculating the carbon dioxide produced by pumping power generation in the pumped storage power station is:

$$
E_{(2)}=\frac{1}{\varphi} T_{w} N_{g} \sum_{i=1}^{n} b_{i} \alpha_{i}
$$

where $\varphi$ is comprehensive efficiency coefficient of pumped storage power station, $T_{w}$ is operating hours of pumped storage power station, $\mathrm{h}, N_{g}$ is storage capacity of pumped storage units , $\mathrm{kW}, b_{i}$ is the type $i$ fuel consumption rate of the rated power generation unit (low consumption rate), $\mathrm{kg} / \mathrm{kWh}$.

The calculation formula of carbon dioxide released in the stable operation of power plant is:

$$
E_{(3)}=\theta_{x} Q
$$

(2) transmission and distribution process

$$
E_{(4)}=\theta_{t} Q
$$

(3) The formula for calculating carbon dioxide emissions is:

$$
E_{2}=24 \sum_{i=1}^{n} N_{i} b_{i} \alpha_{i}+\frac{1}{\varphi} T_{w} N_{g} \sum_{i=1}^{n} b_{i} \alpha_{i}+\theta_{x} Q+\theta_{t} Q
$$

Scenario 2: joint operation of wind power, pumped storage and thermal power

In this scenario, the formula for calculating the carbon dioxide emissions from power generation to electricity consumption is:

$$
E_{3}=24 \sum_{i=1}^{n} N_{i} b_{i} \alpha_{i}+\frac{1}{\varphi} T_{w} N_{g} \sum_{i=1}^{n} b_{i} \alpha_{i}+\theta_{x} Q+\theta_{t} Q-N_{k} h_{j} \varphi b_{1} \alpha_{1}
$$


where $N_{k}$ is the wind power installed capacity under the proportion of $k, \mathrm{~kW}, h_{j}$ is the wind turbine working hours per day in the case of $j$, h.

Based on the formula of scenario 1 and scenario 2, the carbon dioxide emission reduction calculation formula in the process of power generation to electricity consumption is introduced:

$$
M=\left(24-T_{h}\right) \sum_{i=1}^{n} N_{i} b_{\text {高 }} \alpha_{i}+T_{h} N_{1} b_{1} \alpha_{1}-24 \sum_{i=1}^{n} N_{i} b_{i} \alpha_{i}-\frac{1}{\varphi} T_{w} N_{g} \sum_{i=1}^{n} b_{i} \alpha_{i}
$$

\section{Conclusions}

The results are as follows: (1) When the wind power is working on a certain amount of working hours per day, the carbon dioxide emissions from power system will decrease with the increase of wind power installed capacity. It shows that the larger the capacity of the combined use of wind power and pumped storage, the better the environmental benefits of power system. (2) When the installed capacity of wind power is certain, the carbon dioxide emissions of power system will decrease with the increase of the number of working hours per day. The results show that the more wind power is introduced into the power system, the better the environmental benefits are. (3) Comparing the carbon dioxide emissions under the two scenarios, it can be concluded that the carbon dioxide emission is the smallest and the environmental benefits are the best under the combined use of wind power, pumped storage and thermal power. Therefore, it is possible to introduce more renewable energy and pumped storage energy to peak and fill the valley, as well as increase the carbon emission reduction capacity of the power system.

\section{Acknowledgements}

This work was financially supported by the National Natural Fund Project (61471171), the Special Funds for Fundamental Scientific Research Business Fees in Central Universities (2015ZZD08) and the National Science and Technology Project of Power Grid Corp.

\section{References}

[1] Xv Fei, Chen Lei, Jin Heping, Liu Zhenhua. Modeling and application analysis of optimal joint operation of pumped storage power station and wind power [J]. Automation of Electric Power Systems, 2013, 37(1):149-154.

[2] Fan Youmin, Qian Yang. Issues concerning wind energy and wind power generation[J]. Power Equipment, 2009, 23(6):77-79.

[3] Shafiqur R., Luai M. A., Md. Mahbub A., et al. Pumped hydro energy storage system: A technological review [J]. Renewable and Sustainable Energy Reviews, 2015, 44: 586-598.

[4] Henden A L, Doorman G, Helseth A. Economic Analysis of Large-Scale Pumped Storage Plants in Norway[J]. Energy Procedia, 2016, 87:116-123.

[5] Won W, Kwon H, Han J H, et al. Design and operation of renewable energy sources based hydrogen supply system: Technology integration and optimization[J]. Renewable Energy, 2017, 103:226-238.

[6] Muruganantham B, Gnanadass R, Padhy N P. Challenges with renewable energy sources and storage in practical distribution systems[J]. Renewable \& Sustainable Energy Reviews, 2017, 73:125-134.

[7] Haddadian G, Khalili N, Khodayar M, et al. Optimal coordination of variable renewable resources and electric vehicles as distributed storage for energy sustainability $\left.\begin{array}{c}\mathrm{r} \\ \mathrm{r}\end{array} \mathrm{J}\right]$. Sustainable Energy Grids \& Networks, 2016, 6:14-24. 
[8] Abujarad S Y, Mustafa M W, Jamian J J. Recent approaches of unit commitment in the presence of intermittent renewable energy resources: A review[J]. Renewable \& Sustainable Energy Reviews, 2017, 70:215-223.

[9] Khalid M, Ahmadi A, Savkin A V, et al. Minimizing the energy cost for microgrids integrated with renewable energy resources and conventional generation using controlled battery energy storage[J]. Renewable Energy, 2016, 97:646-655.

[10] Iliadis N A, Gnansounou E. Development of the methodology for the evaluation of a hydro-pumped storage power plant: Swiss case study[J]. Energy Strategy Reviews, 2016, 9(1):8-17.

[11] Kong Y, Kong Z, Liu Z, et al. Pumped storage power stations in China: The past, the present, and the future[J]. Renewable \& Sustainable Energy Reviews, 2016.

[12] Papaefthymiou S V, Lakiotis V G, Margaris I D, et al. Dynamic analysis of island systems with wind-pumped-storage hybrid power stations[J]. Renewable Energy, 2015, 74(C):544-554.

[13]Papaefthymiou S V, Papathanassiou S A. Optimum sizing of wind-pumped-storage hybrid power stations inisland systems[J]. Renewable Energy, 2014, 64(2):187-196.

[14]Vojvodic G, Jarrah A I, Morton D P, et al. Forward thresholds for operation of pumped-storage stations in the real-time energy market[J]. European Journal of Operational Research, 2016, 254(1):253-268.

[15]Foley A M, Leahy P G, Li K, et al. A long-term analysis of pumped hydro storage to firm wind power[J]. Applied Energy, 2015, 137:638-648. 